\title{
ATOS DE CURRÍCULO NA PERSPECTIVA DE APP-LEARNING
}

\author{
CURRICULUM ACTS FROM THE APP-LEARNING PERSPECTIVE
}

\section{ACTOS CURRICULARES DESDE LA PERSPECTIVA DE APRENDIZAJE DE APLICACIONES}

\author{
Wallace Carriço de Almeida ${ }^{1}$
}

\section{RESUMO}

Esta dissertação se propõe a compreender o conceito de App-Learning, que SANTAELLA define como o processo de aprendizagem que ocorre apoiado pelo uso de aplicativos de dispositivos móveis, tendo como característica fundamental a multiplicidade de funções, as necessidades dos sujeitos, a portabilidade dos dispositivos e a mobilidade dos sujeitos, que mesmo que estejam fisicamente distantes do contexto educacional conectam-se mutuamente, com o ciberespaço e a cidade. Nossa opção metodológica foi a pesquisa-formação na cibercultura (SANTOS), a multirreferencialidade (ARDOINO) e as pesquisas nos/dos/com os cotidianos (CERTEAU, ALVES). Buscamos compreender como mobilizar Atos de Currículo (MACEDO) no âmbito da disciplina Informática na Educação, do curso de Pedagogia a distância da UERJ, oferecida em parceria com a Fundação Centro de Ciências e Educação Superior a Distância do Estado do Rio de Janeiro (Cecierj) / Consórcio CEDERJ. No exercício de aprender por e com aplicativos, buscou-se compreender como criar atos de currículo em educação online com práticas de App-Learning, descobrir quais os usos que os praticantes culturais fazem de seus dispositivos móveis e como são instituídas as práticas de App-Learning em seu cotidiano para formar docentes na Cibercultura. Como achados da pesquisa apresentam-se as narrativas e imagens, as noções de autoria, fundamentação e acessibilidade além da própria experiência, transformação e aprendizado do pesquisador com os praticantes na reinvenção de aplicativos e práticas.

PALAVRAS-CHAVE: Pesquisa-formação na cibercultura. Docência Online. Cotidianos. Formação de Professores. App-Learning. Atos de Currículo.

\section{ABSTRACT}

This dissertation proposes to understand the concept of App-Learning, which SANTAELLA defines as the learning process that occurs supported by the use of mobile device applications, having as a fundamental characteristic the multiplicity of functions, the needs of the subjects, the portability of the devices and the

Submetido em: 06/07/2020 - Aceito em: 17/08/2020 - Publicado em: 18/08/2020.

${ }^{1}$ Doutorando em Educação pelo Programa de Pós-Graduação em Educação, Contextos Contemporâneos e Demandas Populares (PPGEduc/UFRRJ) da Universidade Federal Rural do Rio de Janeiro e mestre pelo Programa de Pós-Graduação em Educação da Universidade do Estado do Rio de Janeiro (ProPEd/UERJ). Membro do Grupo de Pesquisa Docência e Cibercultura (GPDOC). Professor de Anos Iniciais da Secretaria Municipal de Educação da Prefeitura do Rio de Janeiro. Áreas de atuação: App-Learning, Formação de professores, Cibercultura, Práticas pedagógicas, Educação online e Informática na Educação. 
mobility of the subjects, who, even though they are physically distant from the educational context, connect with each other, with cyberspace and the city. Our methodological option was research-training in cyberculture (SANTOS), multi-referentiality (ARDOINO) and research in / of / with everyday life (CERTEAU, ALVES). We seek to understand how to mobilize Curriculum Acts (MACEDO) within the discipline of Informatics in Education, from the distance Pedagogy course at UERJ, offered in partnership with the Foundation Center for Science and Higher Education at Distance of the State of Rio de Janeiro (Cecierj) / CEDERJ Consortium. In the exercise of learning by and with applications, we sought to understand how to create curriculum acts in online education with App-Learning practices, discover what uses cultural practitioners make of their mobile devices and how App- practices are instituted. Learning in their daily lives to train teachers in Cyberculture. As research findings are presented the narratives and images, the notions of authorship, reasoning and accessibility in addition to the researcher's own experience, transformation and learning with practitioners in the reinvention of applications and practices.

KEYWORDS: Research-training in cyberculture. Online Teaching. Daily life. Teacher training. App-Learning. Curriculum Acts.

\section{RESUMEN}

Esta disertación propone comprender el concepto de App-Learning, que SANTAELLA define como el proceso de aprendizaje que se produce respaldado por el uso de aplicaciones de dispositivos móviles, teniendo como característica fundamental la multiplicidad de funciones, las necesidades de los sujetos, la portabilidad de los dispositivos y la movilidad de los sujetos, quienes, aunque están físicamente distantes del contexto educativo, se conectan entre sí, con el ciberespacio y la ciudad. Nuestra opción metodológica fue la investigación-capacitación en cibercultura (SANTOS), multireferencialidad (ARDOINO) e investigación en / de / con la vida cotidiana (CERTEAU, ALVES). Buscamos entender cómo movilizar las Actas Curriculares (MACEDO) dentro de la disciplina de Informática en Educación, desde el curso de Pedagogía a distancia en la UERJ, ofrecido en colaboración con el Centro de la Fundación para la Ciencia y la Educación Superior a Distancia del Estado de Río de Janeiro ( Cecierj) / Consorcio CEDERJ. En el ejercicio del aprendizaje mediante y con aplicaciones, buscamos comprender cómo crear actos curriculares en educación en línea con las prácticas de App-Learning, descubrir qué usos hacen los profesionales de la cultura de sus dispositivos móviles y cómo se instituyen las prácticas de App. Aprendiendo en su vida diaria a capacitar docentes en Cibercultura. A medida que se presentan los resultados de la investigación, las narraciones e imágenes, las nociones de autoría, razonamiento y accesibilidad, además de la propia experiencia, transformación y aprendizaje del investigador con los profesionales en la reinvención de aplicaciones y prácticas.

PALABRAS CLAVE: Investigación-formación en cibercultura. Enseñanza en línea. Vida diaria. Formación de profesores. Aprendizaje de aplicaciones. Actos curriculares.

\section{INTRODUZINDO A PESQUISA}

A presente dissertação é fruto de uma pesquisa-formação na cibercultura que foi o foco de uma dissertação de mestrado que teve como campo de pesquisa o cotidiano da disciplina de "Informática na Educação" do curso de licenciatura em Pedagogia a distância pela UERJ/CEDERJ/UAB. A disciplina conta com um grupo no Facebook e está arquitetada no Moodle, que é uma plataforma de aprendizagem a distância baseada em software livre onde todos interagem criando e cocriando o conhecimento e suas aprendizagens. 
As perguntas que motivaram o início da minha jornada acadêmica se tornaram dilemas conforme eu me formava professor. Enquanto era preciso que eu aprendesse a ensinar, eu ainda tentava dominar a arte de aprender. Muitas vezes partimos com uma pergunta e quando retornamos trazemos conosco um mundo de novas perguntas tão instigantes quanto àquela que nos fez partir. É nesse momento que percebemos que a jornada não acontece lá fora, no mundo a se perscrutar, não é lá o seu caminho, mas sim dentro do itinerante, que ao ser e mover-se pelo mundo amplia o seu próprio e tem como recompensa a capacidade de fazer novas perguntas.

$\mathrm{Eu}$ sou uma pessoa aficionada pelo digital, principalmente por entender que as tecnologias digitais em rede permitem que possamos levar para a sala de aula o cinema, as artes em geral, os cotidianos, as ciências, as culturas do mundo. (SANTOS, 2014).

Percebi que se o digital em rede estava presente e funcionava tão bem no meu cotidiano, poderia estar presente também na forma como eu absorvia o conteúdo na universidade. Assim passei a traçar novas estratégias. Ao descobrir que os aplicativos também poderiam me proporcionar outras experiências de aprendizagem passei a associá-los as leituras, as aulas e a tudo aquilo que eu podia relacionar com a aprendizagem "digitalizando" o meu cotidiano da cidade e da universidade no ciberespaço. Essa prática me ajudou a mudar a linguagem com a qual eu vinha me relacionando comigo mesmo, criando pontes entre todos os mundos que eu frequentava, estabelecendo assim as primeiras "relações diplomáticas" daquele universo da educação e do digital que se tornaria meu lar.

Desse modo, a primeira grande pergunta que daria início a minha jornada seria: como se aprende na era digital? Uma pergunta que até hoje move o meu pensamento em cada ato praticado como docente em uma escola pública do município do Rio de Janeiro. Percebendo que tudo o que eu ensino, mas também a forma como ensino precisa seguir uma dinâmica similar ao tempo cultural em que eu vivo, evitando assim o estranhamento cultural entre o cotidiano e as práticas escolares, ou (no meu caso) universitárias.

\section{PESQUISANDO A FORMAÇÃO DOCENTE EM APP-LEARNING}

Entendendo que a formação docente, o cenário social e a estrutura escolar são alguns dos problemas que perpetuam essa cultura do offline, surge a necessidade de pesquisar e discutir mais sobre esse assunto questionando, acima de qualquer outra, a minha prática e os achados do cotidiano na perspectiva de compreender agora não somente como se aprende, mas como também como se ensina na era digital.

No exercício de aprender por e com aplicativos durante a formação de discentes e docentes da Universidade do Estado do Rio de Janeiro buscamos compreender: como criar atos de currículo em educação online com práticas de App-Learning? Quais os usos que os 
praticantes culturais fazem de seus dispositivos móveis e como são instituídas práticas de App-Learning? Como fazer a pesquisa acadêmica em tempos de cibercultura em perspectiva de App-Learning?

Buscando compreender como criar e propor atos de currículo em educação online com práticas de App-Learning, investimos em um desenho didático aberto onde pudéssemos situar e abrir nossas práticas a novas experiências, construindo o currículo ao longo do processo formativo com os praticantes. Desse modo, poderíamos, para além de compreender seus usos, promover também verdadeiras experiências formativas de educação online. Situando nossa prática na proposta de entendimento de que para se pesquisar na cibercultura é preciso atuar como praticante cultural produzindo dados em rede, não poderíamos conceber que nossos interlocutores nessa pesquisa seriam meros informantes, mas sim atuantes produtores de culturas e saberes.(SANTOS, 2015, p. 10; 2019, p. 20).

Nesse sentido, iniciei minha pesquisa de mestrado tentando compreender qual seria a melhor abordagem para experimentar essas vivências com os aplicativos em uma turma de graduação em um contexto educacional e formativo e encontrei no conceito de atos de currículo "uma incessante atividade etnometódica e fonte de análise de práticas curriculares", como conceitua Roberto Sidnei Macedo (2013).

Para Macedo, o conceito de atos de currículo está pautado no argumento de que interativamente, numa incessante atribuição de sentidos, todos os envolvidos com as questões curriculares, não somente professores, mas também os alunos são atores curriculantes na perspectiva de que detêm a capacidade de alterar as cenas curriculares e serem coautores dos seus processos de aprendizagem (formação) pelos seus atos de currículo. Afinal, é indo ao encontro dos atos de currículo, suas realizações, seus motivos, suas crenças, seus pontos de vista e justificativas é que podemos compreender os processos pelos quais as pessoas constroem cotidianamente currículos, seus sentidos e significados (MACEDO, 2013, pg 430)

Assim, ao vivenciar o campo da pesquisa, intencionei na horizontalidade dos saberes, buscando descobrir com eles (os praticantes) suas táticas de aprendizagem entendendo principalmente como articulam os dispositivos móveis em contexto educacional, visando a utilização de aplicativos para otimizar esse processo. É interessante também conceber essa perspectiva do ponto de vista dos praticantes, onde precisam sair da zona de conforto da passividade na qual estão situados desde os anos iniciais da educação para atuarem como protagonistas de seu processo formativo onde sua experiência e sua prática tem valor curricular.

Nesse momento, a pesquisa buscou descobrir quais são os aplicativos e quais são os usos que os praticantes da graduação da faculdade de educação da UERJ fazem deles em seu processo de aprendizagem, visando traçar estratégias de utilização e intencionalidades. Proporcionando através de criação de atos de currículo em uma disciplina da graduação, uma alternativa na formação oferecida no nível superior. Acreditando que o trabalho de mobilizar 
essas competências nesses novos educadores possa gerar autoria potente na formação de educadores ciberculturais.

Nossa investigação está organizada em seis partes que constituem os capítulos e as etapas da jornada compreendida nesse texto. Abordamos na primeira parte nossa itinerância revisitando alguns dos caminhos percorridos como educador em formação passando pelos dilemas que nos implicaram em direção à partida do porto no início da pesquisa.

Na segunda parte, disserto a respeito do conceito de sociedade em rede partindo de sua concepção aos tempos atuais, revelando ao leitor os movimentos do mar da história da comunicação de massa à cibercultura. Nesse capítulo fizemos um mapeamento dos acontecimentos historiográficos pelos quais perpassaram o mar de inovações tecnológicas que proporcionaram o advento do cenário sociotécnico necessário para o surgimento da cibercultura. A partir da pergunta: 'como chegamos até aqui?' inauguramos a primeira parte desse capítulo partindo da Revolução Industrial até o surgimento dos primeiros smartphones e suas lojas de aplicativos, enquanto na segunda parte, tratamos de como a cibercultura vem se modificando em meio a perspectiva da mobilidade.

Apresento na terceira parte o conceito de educação online que é um fenômeno da cibercultura em contexto com a prática de App-Learning como um farol de inovação na promoção de conteúdos em atos de currículo baseados nos conceitos de mobilidade, interatividade e hipertexto. Conforme a fundamentação teórica (SANTOS, 2005), entendemos que a educação online é um fenômeno da cibercultura, uma vez que podemos atribuir à educação online os mesmos princípios da cibercultura (SANTOS, 2013, pg. 290). A liberação do polo de emissão, o princípio da conexão em rede, e a consequente reconfiguração sociocultural a partir de novas práticas produtivas e recombinatórias (LEMOS, 2006) são também base fundante da educação online. Na educação online o conteúdo apresentado na tela apropria-se de práticas que promovem a interatividade (SILVA, 2000) e a colaboração entre todos os envolvidos na dinâmica de ensinar e aprender na cibercultura. Os praticantes traçam assim uma nova dinâmica comunicacional nos ambientes virtuais de aprendizagem (AVA), através dos fóruns e chats, e através da mobilidade perpetuam esse diálogo em todo o tempo e em todos os lugares (ubiquidade) onde se acham em conexão. Assim a sala de aula não está mais distante, e sim muito mais perto como nunca esteve antes, ao alcance da palma da mão em telas de todos os tamanhos e gostos disponíveis a escolha do consumidor.

Discutimos neste trabalho o conceito de App-Learning, que aqui definimos como o processo de aprendizagem que ocorre apoiado pelo uso de aplicativos de dispositivos móveis, tendo como característica fundamental a multiplicidade de funções, as necessidades dos sujeitos, a portabilidade dos dispositivos e a mobilidade dos sujeitos, que mesmo que estejam fisicamente distantes do contexto educacional conectam-se mutuamente, com o ciberespaço e a cidade. 
Assim como na dinâmica do hipertexto, a lógica dos aplicativos permite que, através de interações na tela do dispositivo, se navegue por múltiplas interfaces de informação de forma associativa, não linear, onde a concepção do conhecimento dá-se a partir de blocos de informações captadas de diferentes partes de conteúdo absorvido das mais diversas formas possíveis. Essa prática é vivida em sua totalidade em nosso tempo, de modo que podemos perceber que essas novas formas de interação com o conhecimento revelam um novo estilo de aprendizagem que pode proporcionar uma forma de auto reconhecimento narrativo através da pluralidade de experiências e formatos, criando o poder de sua própria linguagem em um mundo de escopo infinito.

Na quarta parte apresento a epistemologia e a metodologia que, como uma bússola, norteiam essa pesquisa-formação na cibercultura. Abordo também o contexto da pesquisa, onde apresento os praticantes e o dispositivo da pesquisa, que é percebido na dialógica plural e multirreferencial característica dos ambientes online. Aponto para as conversações e narrativas que surgem no ciberespaço e enuncio as noções subsunçoras que surgem da prática docente em consonância com as invenções dos praticantes.

$\mathrm{Na}$ quinta parte apresentamos o processo de análise de dados, ou seja, o exame minucioso das narrativas, conversas, imagens e vídeos gerados em contexto de pesquisa. Apuramos esses dados propondo um consenso entre tudo aquilo que vivenciamos na prática e o que dizem os nossos parceiros intelectuais em virtude dos tesouros descobertos na pesquisa. No esforço de tentar apreender os achados que emergem de nossa pesquisa, elegemos algumas categorias analíticas que irão, em suma, acolher e perceber o conjunto de dados e sentidos vislumbrados em nossa investigação. Essas categorias analíticas são, segundo Santos (2005, p. 153), fruto de um movimento constante de análise dialógica entre a teoria e a empiria, em um processo de aprendizagem significativa, que atendendo o conceito central da teoria da aprendizagem, subsumiria uma nova noção significativa à estrutura cognitiva familiar preexistente do indivíduo. As noções subsunçoras surgem, portanto, da atividade interpretativa do pesquisador mediante à análise dos dados que emergiram das situações, das ocorrências, dos achados e das divergências da pesquisa, sendo atualizadas e modificadas a cada nova interação proporcionada pela empiria ou pela teoria durante esse processo investigativo.

Essas noções são apresentadas em forma de recortes dos achados já apresentados no decorrer de nosso empreendimento, mas que agora amparados pelas nossas parcerias intelectuais e teóricas, delineiam uma análise dos achados da pesquisa. Denominadas "applicando" em acessibilidade, "applicando" em cibercultura e "applicando" em autoria elas compõem o desejo de mobilizar essas competências não somente na formação de novos educadores, como também de minha própria formação como docente na cibercultura.

A primeira noção trata da importância de uma universalidade do acesso à Web como direto de todos os praticantes culturais e a questão de garantir a todos os usuários uma mesma autonomia de experiência. Um movimento que já possui de legislação específica acerca da 
adoção de medidas necessárias para garantir a acessibilidade de informação e conteúdo para pessoas com deficiência, mas que nem sempre é praticado nos contextos gerais do cotidiano.

O movimento de uma praticante da disciplina iniciou uma revolução em nossas práticas docentes, afetando todo o coletivo envolvido na disciplina, como também a minha própria percepção dos surdos ao meu redor. Como uma pedra que é arremessada no meio do lago, sua invenção proporciona ondas de dispersão de protagonismo e inclusão mediante uma calmaria de inatividade de uma maioria estabelecida.

Aprender com a praticante como a minha proposta poderia ser muito mais do que eu havia concebido foi, sem sombra de dúvidas, um dos maiores achados dessa pesquisa e vai motivar o surgimento de muitas outras pesquisas no assunto.

A segunda noção trata da importância de um constante movimento de integração social docente, em perspectiva de integrar práticas formativas que minimizem as inseguranças acerca da utilização de dispositivos e recursos digitais tecnológicos não somente em sala de aula, como também em sua vivência cotidiana.

Trabalhando com os praticantes descobrimos exemplos de protagonismo autoral docente que deseja gerar experiências significativas de aprendizagem na cibercultura. Ao final desse momento esses futuros educadores deram uma aula de como podemos abrir mão das nossas limitações e dificuldades e nos unirmos em busca de juntar o máximo certezas para enfrentar as incertezas

A última noção trata do entendimento do papel da autoria nas questões que envolvem o processo de pesquisa de práticas de ensinoaprendizagem inspiradas na efervescência do compartilhamento e colaboração dos indivíduos.

Destacamos a importância da manifestação da autoria no surgimento de processos de interação entre indivíduos singulares, que em perspectiva de conectividade em rede, trocam entre si e com o mundo através de experiências significativas. Abandonando o simbolismo e o significado da autoria como um exercício individual para aproximar-se cada vez mais de seus pares em busca de diminuir limitações e fronteiras para criar em pervasividade novas concepções do que é ser um docente autor na cibercultura.

Por fim, cabe a sexta e última parte a difícil missão de narrar o percurso dessa jornada e promover um convite para novas empreitadas e novos viajantes que ousarem viver a mesma aventura.

\section{CONSIDERAÇÕES FINAIS}

O investimento que aqui se propôs como estudo está ancorado nas reflexões acerca de entender como os aplicativos, a mobilidade e o ciberespaço podem contribuir para os 
processos de ensino aprendizagem no atual contexto da cibercultura em espaços formais e não formais de aprendizagem.

Seguir essa estratégia pode nos ajudar a entender como podemos criar atos de currículo na perspectiva de aprendizagem com os aplicativos dos dispositivos móveis. Afinal, não podemos correr o risco de estarmos preparando os alunos para um futuro que não podemos descrever claramente, mas sim usar o digital em rede, aprendendo e fazendo coletivamente para exercer a cidadania.

Muitas são as demandas implicadas nesse processo, mas o fazemos na perspectiva de proporcionar algumas das dinâmicas que eu mesmo gostaria de ter experimentado no meu processo de formação como aluno deste mesmo curso de pedagogia na UERJ.

Aceitar e processar essa realidade em todo o seu potencial se torna indispensável, mesmo que de forma experimental, quando interagimos o tempo todo com indivíduos que mais do que alunos, são protagonistas dessa revolução cultural. Já vivenciamos várias dessas práticas em nosso cotidiano de forma natural, sendo assim, por que não naturalizar algumas dessas práticas em um contexto educacional? Principalmente quando precisamos mobilizar essas vivências como prática s sociais.

\section{REFERÊNCIAS:}

ALVES, Nilda. Decifrando o pergaminho - o cotidiano das escolas nas lógicas das redes cotidianas. In: OLIVEIRA, Ines Barbosa de; ALVES, Nilda. (Org.). Pesquisa no/do cotidiano das escolas: sobre redes de saberes. Rio de Janeiro: DP\&A, 2001.

ALVES, Nilda. Pesquisa nos/dos/com os cotidianos das escolas: sobre rede de saberes. Petrópolis, RJ: DP et Alii, 2008

AMARAL, Sérgio.; BARROS, Daniela. Estilos de aprendizagem no contexto educativo de uso das tecnologias digitais interativas, 2007. Disponível em: $<$ http://bit.ly/estilosaprendizagem. $>$ Acesso em Junho de 2017.

BACKES, Luciana. As manifestações da autoria na formação do educador em espaços digitais virtuais. Revista de Educação, Ciência e Cultura, v. 17, n. 2, jul./dez. 2012. Disponível em: <http://bit.ly/autoriabackes.> Acesso em Novembro de 2017.

CAROLEI, Paula; e TORI, Romero. Aurasma: aumentando e gamificando a realidade. In: COUTO, Edvaldo; PORTO, Cristiane; SANTOS, Edmea (Org.). App-learning: experiências de pesquisa e formação. Salvador: EDUFBA, 2016.

CARVAlHO, Felipe. Atos de Currículo na Educação Online. ProPEd - UERJ: 2015. Disponível em: <http://bit.ly/2vF1Pci.> Acesso em Outubro de 2016.

CASTELLS, Manuel. A Galáxia da Internet: Reflexões sobre a Internet, os negócios e a sociedade. Rio de Janeiro: Jorge Zahar Editor, 2003 
CERTEAU, Michel de. A invenção do cotidiano: 1. Artes de fazer. Petrópolis, RJ: Vozes, 1994.

D’ÁVILA, Carina. SANTOS, Edméa. Imagens voláteis e formação de professorxs: dispositivos tecnológicos e lúdicos para as práticas pedagógicas, Revista Entreideias, Salvador, v. 3, n. 2, p. 113-127, jul./dez. 2014. Disponível em: 〈http://bit.ly/2Oxd4KT. $>$ Acesso em Agosto de 2018.

FREIRE, Paulo. Pedagogia da autonomia: saberes necessários à prática educativa. São Paulo: Paz e Terra, 1996.

LARROSSA, Jorge. Experiência e alteridade em educação. Reflexão e Ação, vol.9, n.2, 2011. Disponível em: 〈http://bit.ly/2Bd9rrY〉. Acesso em Agosto de 2018

LEMOS, André. Mídia locativa e território informacional. SANTAELLA, Lucia; ARANTES, Priscila (Org.). Estéticas tecnológicas: novos modos de sentir. São Paulo: EDUC, 2008.

LEMOS, André. Ciberespaço e tecnologias móveis: processos de territorialização e desterritorialização na cibercultura. In: MÉDOLA, Ana Silvia; ARAÚJO, Denise; BRUNO, Fernanda (Org.). Imagem, visibilidade e cultura midiática. Porto Alegre: Sulina, 2007.

LEMOS, André. Cibercultura como território recombinante. In: Territórios Recombinantes. Instituto Goethe (ICBA), Salvador, 2006. Disponível em <http://bit.ly/recombinante. $>$ Acesso em Setembro de 2017.

LÉVY Pierre. Cibercultura. São Paulo: Ed. 34, 1999

LÉVY Pierre. A Inteligência Coletiva: Por uma Antropologia do Ciberespaço. São Paulo: Loyola, 2007

MACEDO, Roberto Sidnei. Atos de currículo e Autonomia Pedagógica: o socioconstrucionismo curricular em perspectiva. Petrópolis, RJ: Vozes, 2013.

MACEDO, Roberto Sidnei. Currículo: campo, conceito e pesquisa. Petrópolis, RJ: vozes, 2007.

MACEDO, Roberto Sidnei. Trajetória, itinerário, itinerância e errância: perspectivando o currículo enquanto crisálida. ANPED 2000. Disponível em: 〈http://bit.ly/2MFCCVK. $>$ Acessado em Julho de 2018.

MIRANDA, Antonio; SIMEAO, Elmira and MUELLER, Suzana. Autoria Coletiva, Autoria Ontológica e Intertextualidade na Ciência: Aspectos Interdisciplinares e Tecnológicos. 2007, vol.36, n.2, pp.35-45. Disponível em: <http://bit.ly/2MmOE9m.> Acesso em Maio de 2018. 
MORIN, Edgar. Da necessidade de um pensamento complexo, Para navegar no século XXI: tecnologias do imaginário e cibercultura. 3. ed. Porto Alegre: Sulinas/Edipucrs, 2003

PRETTO, Nelson De Luca. Redes colaborativas, ética hacker e educação 2010. Disponível em: <http://bit.ly/2vDNqNH > Acesso em Julho de 2018

SANTAELLA, Lucia. Comunicação ubíqua: repercussões na cultura e na educação - São Paulo: Paulus, 2013.

SANTAELlA, Lucia. A estética política das mídias locativas. Instituto de Estudios Sociales, Bogotá, 2008.

SANTAELlA, Lucia. Cultura das Mídias. São Paulo: Experimento. 1996.

SANTAELLA, Lucia. Linguagens líquidas na era da mobilidade. São Paulo: Paulus. 2007.

SANTAELLA, Lucia. App-learning e a imaginação criativa a serviço da educação [Prefácio]. In: COUTO, Edvaldo; PORTO, Cristiane; SANTOS, Edmea (Org.). App-learning: experiências de pesquisa e formação. Salvador: EDUFBA, 2016.

SANTOS, Edméa Oliveira dos. Educação online: cibercultura e pesquisa-formação na prática docente. Tese de doutorado. Faculdade de Educação, UFBA, Salvador. 2005. Disponível em: <http://bit.ly/2OvON7X. > Acesso em Junho de 2016

SANTOS, Edméa Oliveira dos. Pesquisa-formação na cibercultura. Santo Tirso: Whitebooks, 2014.

SANTOS, Edméa Oliveira dos; CARVALHO, Felipe da Silva Ponte; e PIMENTEL, Mariano. Mediação docente para colaboração: notas de uma pesquisa-formação na cibercultura. Campinas, SP, Revista Educação Temática Digital (ETD), v.18, n.2, p. 23-42, jan.abr.2016. Disponível em: <http://bit.ly/2B7JTwc.> Acesso em Janeiro de 2018.

SANTOS, Edméa. COLACIQUE, Rachel. CARVALHO, Felipe. A autoria visual na internet: o que dizem os memes? Quaestio, Sorocaba, SP, v. 18, n. 1, p. 135-157, maio 2016. Disponível em: <http://bit.ly/2w33IPy. > Acesso em Janeiro de 2018.

SANTOS, Edméa. PONTE, Felipe. ROSSINI, Tatiana. Autoria em rede: uma prática pedagógica emergente. Rev. Diálogo Educ., Curitba, v. 15, n. 45, p. 515-536, maio/ago. 2015. Disponível em: <http://bit.ly/2MGjneJ.> Acesso em Julho de 2018.

SILVA, Marco. Sala de aula interativa. Rio de Janeiro: Quartet, 2000

SILVA, Marco. Formação de professores para a Docência Online. Braga: Universidade do Minho, 2009. Disponível em: <http://bit.ly/2B4TbJ9.> Acesso em Outubro de 2017.

Este é um artigo de acesso aberto distribuído sob os termos da Licença Creative Commons Atribuição Não Comercial-Compartilha Igual (CC BYNC- 4.0), que permite uso, distribuição e reprodução para fins não comerciais, com a citação dos autores e da fonte original e sob a mesma licença. 